\title{
ARTICLE
}

\section{Recent issues in high-level perception}

\section{Grace Helton}

Princeton University

\section{Correspondence}

Grace Helton, Princeton University, Society of Fellows in the Liberal Arts, Joseph Henry House, Princeton, NJ 08544.

Email: grace.helton@gmail.com

\begin{abstract}
Recently, several theorists have proposed that we can perceive a range of high-level features, including natural kind features (e.g., being a lemur), artifactual features (e.g., being a mandolin), and the emotional features of others (e.g., being surprised). I clarify the claim that we perceive high-level features and suggest one overlooked reason this claim matters: it would dramatically expand the range of actions perception-based theories of action might explain. I then describe the influential phenomenal contrast method of arguing for high-level perception and discuss some of the objections that have been raised against this strategy. Finally, I describe two emerging defenses of high-level perception, one of which appeals to a certain class of perceptual deficits and one of which appeals to adaptation effects. I sketch a challenge for the latter approach.
\end{abstract}

\section{KEYWORDS}

adaptation effects, high-level perception, perception-cognition divide, phenomenal contrast method, unilateral neglect, visual experience

\section{1 | INTRODUCTION}

Suppose there is a cat lounging in a hammock. The weight of the cat's body pushes the fabric of the hammock down, creating a bulge in the bottom of the hammock. ${ }^{1}$ In looking at this scene, what do you visually perceive? On one view, you perceive merely the shapes and colors of the cat and of the hammock. On another view, you visually perceive the colors and shapes of the cat and of the hammock, and you additionally perceive the cat as a cat, the hammock as a hammock, and the bulge in the hammock as caused by the weight of the cat. On this latter view, visual perception can represent a range of high-level features, since it can represent features other than the visual domain's paradigmatic low-level features of shape and color.

Recently, several theorists have proposed that we can perceive a range of high-level features, including natural kind features (e.g., being a cat), artifactual features (e.g., being a hammock), and event-causal features (e.g., being the cause of a hammock's bulge; Bayne, 2009; Butterfill, 2009; O'Callaghan, 2008; Scholl \& Tremoulet, 2000; Siegel, 2006, 2009, 2010). Other recently proposed high-level percepts include agency features (e.g., being oneself the cause of a window's shattering), action features (e.g., being graspable), the emotional and intentional features of others (e.g., being surprised), social features (e.g., being masculine), and moral features (Bayne, 2009, 2011; Begby, 2011; Block, 
2014; Butterfill, 2009, 2015; Cullison, 2010; Di Bona, In preparation; Fish 2013; Helton, 2015; Masrour, 2011; Nanay, 2011, 2012; Scholl \& Gao, 2013; Siegel, 2005, 2010, 2014; Toribio, 2015a, 2015b; Van Gulick, 1994; Wisnewski, 2015).

Despite this proliferation of proposed high-level percepts, some theorists deny that we perceive any-or manyhigh-level features (Brogaard, 2013; Byrne, 2009; Pautz, 2008; Prinz, 2013; Sosa, 2015; Tye, 1995, 2000). An additional position has also emerged, on which there is no fact of the matter about whether we perceive high-level features (Logue, 2013).

In this paper, I clarify the claim that we perceive high-level features and suggest some reasons the claim matters (Section 2). I then describe the influential phenomenal contrast method of arguing for high-level perception (Section 3) and discuss some of the objections that have been raised against this strategy (Section 4). I next consider other defenses of high-level perception, including an approach which appeals to adaptation effects, and I sketch a challenge for this approach (Section 5). I close with a summary (Section 6).

\section{2 | HIGH-LEVEL PERCEPTION AND WHY IT MATTERS}

The distinction between low-level and high-level features is generally made on the basis of a list of each of the relevant sensory modality's paradigm low-level features. Any feature that is not among the relevant modality's low-level features is a high-level feature (Macpherson, 2011, 9). In the visual modality, paradigm low-level features include shape and color; in the auditory modality, paradigm low-level features include volume and pitch; and so on for the other sensory modalities.

This list-based strategy of demarcating low-level from high-level features might seem surprisingly unprincipled, both in that it does not draw the distinction in an explanatorily satisfying way and in that it leaves open whether certain features are low-level or high-level. But this loose approach reflects the aim of the debate, which is to determine which features we can perceive. The further classification of those features as low level or high level serves merely as imperfect short hand for whether those features are among those that have traditionally been recognized as percepts (Bayne, 2009, 388).

The claim that perception represents high-level features is generally construed as the claim that typical adults sometimes perceive at least some high-level features (Bayne, 2009; Macpherson, 2011). This claim is also generally construed as the claim that perception represents high-level features in a way that contributes to the "phenomenal" or subjectively accessible aspect of perception. Thus, the claim that we can visually perceive some object as a cat is committed to the claim that the attribution of being a cat to that object makes a constitutive contribution to "what it is like" for us to see that object (Siegel, 2007, 2009; Bayne, 2009; Nanay, 2012). ${ }^{2}$

Some advocates of high-level perception claim that high-level perception is ontically on a par with paradigm lowlevel perceptual experiences, such as seeing something as purple or feeling something as cold (Butterfill, 2015; Siegel, 2010). One possible way of spelling out this claim is as follows: if and insofar as a completed cognitive science must account for (say) the visual experience of color, so too must a completed cognitive science account for the perceptual experience of high-level features. The claim that high-level perception is, in some sense, as real as low-level perception is consistent with the claim that high-level perception emerges from certain aspects of low-level perception.

Notably, the claim that perception represents high-level features neither entails nor is entailed by the claim that perception is cognitively penetrable (Brogaard \& Chomanski, 2015). Some perceptual experience is cognitively penetrable just in case it can be rationally influenced in a certain way by some thought. For instance, if a subject's belief that bananas are yellow makes subsequently presented bananas look yellower to her than they otherwise would, and if this influence does not proceed via intramodular processing or via a shift in the subject's attention, then this subject's color perception is cognitively penetrable (Macpherson, 2012; Pylyshyn, 1999).

If we can perceive high-level features, this capacity might be the result of some kind of cognitive influence on perception, but it might not. Instead, this capacity might be innate, perhaps of the sort which permits fine-tuning during a 
subject's developmental period but which is relatively fixed in the mature subject (Toribio, 2015b). Likewise, if our perceptual experiences are cognitively penetrable, this fact might result in the perception of high-level features, but it might not. Rather, cognitive states might influence the perception of low-level features, such as color and shape, without contributing to the creation of novel, high-level percepts.

The issue of whether we perceive high-level features has the potential to impact important issues outside of philosophy of perception. Consider a foundationalist approach to epistemic justification, on which beliefs about the external world are either justified directly, by perceptual states, or else indirectly, by other beliefs which are themselves perceptually justified. On a conservative drawing of the perceptual landscape, the foundationalist must explain how our many beliefs about the external world derive justification from a relatively impoverished base of perceptual experiences. On a more generous rendering of the perceptual landscape, the foundationalist's workload would appear to be lighter, as she can appeal to a comparatively rich base of perceptual experiences to explain how our full range of beliefs is justified (Lyons, 2005; Macpherson, 2011; Masrour, 2011; cf. Silins, 2013; Sosa, 2015).

An additional, underappreciated reason it matters whether we perceive high-level features is that if we do, this fact might expand the available explanations of action, particularly on the perception-based model of action, on which at least some actions are mediated by a relevant desire and a relevant perceptual state, without the assistance of a mediating thought (Nanay, 2013, ch. 4). On this model, the hiker who steps over a fallen tree in her path might do so because she wishes to continue moving forward and because she visually perceives the tree as impermeable. She needn't have additionally formed the thought that the tree is impermeable.

If perception does not only merely represent low-level features such as shape and color but also represents highlevel features such as being delicious or being unclean, this would dramatically expand the range of actions that the perception-based model might explain. For instance, it would be at least prima facie plausible that the subject who compulsively washes her hands does so because of a pervasive misperception that her hands are unclean, rather than because of a pathological belief that her hands are unclean.

\section{3 | THE PHENOMENAL CONTRAST ARGUMENT}

In recent work, the most influential strategy of arguing for high-level perception is the phenomenal contrast argument, which has been developed most extensively by Susanna Siegel. ${ }^{3}$ The phenomenal contrast argument proceeds in two steps: first, it is argued that the felt difference between a certain carefully chosen pair of phenomenally contrastive mental states is due to a difference in content, such that one of these mental states represents some relevant highlevel feature $\Phi$, whereas the other does not. Second, it is argued that the mental state that represents $\Phi$ is a perceptual experience, rather than a thought or other non-perceptual attitude (Siegel, 2005, 2007; 2010, 99-108, 121-139; Siewert, 1998, 255-262). Note that the advocate of the phenomenal contrast argument does not claim that all phenomenal contrasts are explained by high-level perception. Rather, her claim is that, as a matter of contingent fact, at least some such contrasts are explained by high-level perception.

Consider by way of illustration how the phenomenal contrast argument might be used to support the claim that we perceive artifactual features, such as being a stethoscope or being a mandolin. Suppose you are not particularly familiar with stringed instruments. Perhaps you can distinguish guitars from violins, but you cannot distinguish similar-looking instruments, such as mandolins and lutes. You then begin a job working for a luthier and learn how to examine, repair, and build a variety of stringed instruments, including many mandolins. After some time, mandolins seem to take on a distinctive appearance. Just by looking at them, you can immediately and effortlessly distinguish them from lutes.

Now, compare the following two mental states: the mental state you had when viewing a mandolin before your training, and the mental state you have when viewing a mandolin now, in your post-training state. Plausibly, there is a difference in the subjective quality of these experiences, in "what it is like" to be in them. The advocate of high-level perception will argue that the best explanation of this difference is that in your naïve state, you did not visually 
perceive the mandolin as a mandolin, whereas in your informed state, you do visually perceive the mandolin as a mandolin.

Spelled out, here is the phenomenal contrast argument for mandolin perception:

1. There is a certain phenomenal difference between the mental state you have when viewing a mandolin in your naïve state and the mental state you have when viewing a mandolin in your expert state.

2. The phenomenal difference between your two mental states is due to the fact that in your naïve state, you do not represent the mandolin as a mandolin, whereas in your informed state, you do represent the mandolin as a mandolin.

3. The "mandolin" representation (if any) in your expert state is a visual experience.

4. In your expert state, you visually perceive the mandolin as a mandolin.

There are two things to note about this argument. First, for the sake of concreteness, I will center the discussion around the "mandolin" argument, but this general pattern of argument might be used to defend most any high-level perceptual claim, so as long as a pair of relevantly contrastive mental states is available. ${ }^{4}$ Second, the argument's second and third premises are supported by inferences to the best explanation (Siegel, 2013).

\section{4 | OBJECTIONS TO THE PHENOMENAL CONTRAST METHOD}

There are three main challenges to the phenomenal contrast argument for mandolin perception, corresponding to each of the argument's premises. These objections might also be made against contrast-based arguments for other kinds of high-level perception.

\section{1 | First objection: which is the relevant phenomenal contrast?}

The first objection targets the argument's first premise, which states that there is a certain phenomenal contrast between your naïve and expert mental states. One way to reject this premise begins with the observation that any two bits of conscious life will invariably contain a multitude of phenomenal differences, owing to differences in overall mood; the presence of hunger, thirst, or fatigue; associated thoughts and feelings; associated sensory and perceptual experiences; and so on. Thus, the question arises of how to pick out the correct phenomenal contrast in a way that does not rely on a question-begging description, such as the one that is due to high-level perception (Chudnoff, 2015; Koksvik, 2015, 329).

To defuse this worry, the advocate of the phenomenal contrast strategy might claim that we can ostend the relevant phenomenal difference while remaining neutral about what explains this difference. Consider that ostension can succeed even when it is accompanied by an inaccurate description of the relevant object. You can successfully ostend someone you take to be a man drinking gin, even if that person is really a woman drinking vodka. Likewise, you might ostend the phenomenal difference between your naïve and informed mental states by "pointing" at the "mandolin" component in the latter state, even if it should turn out that there is no "mandolin" element, since what you took to be the "mandolin" element was really (say) a feeling of familiarity elicited in response to a mandolin. This sort of ostension would not beg the question of whether there is a "mandolin" element of experience, nor would it beg the question of whether that "mandolin" element, if any, is perceptual.

One concern about the ostensive method of identifying the relevant contrast is that there is some reason to think that ostension requires some accurate guiding descriptors. Consider that even in the case in which you successfully ostend a woman drinking vodka who you mistook for a man drinking gin, there are likely other accurate descriptors which help to guide your ostension, such as the person holding a drink. If ostension requires at least some accurate descriptors, then it is not obvious that ostension will permit us to pick out the relevant phenomenal contrast in a 
non-question-begging way, since it is not obvious that there are available accurate descriptors which do not beg the question of whether the contrast is due to high-level perception (Koksvik personal communication).

\subsection{Second objection: the high-level feature is not represented}

A different objection to the phenomenal contrast argument rejects the argument's second premise, which states that the phenomenal contrast is due to the fact that in your naïve state, you do not represent the mandolin as a mandolin, whereas in your expert state, you do represent the mandolin as a mandolin. One way of rejecting this claim is to suggest that it is merely a feeling of familiarity which explains the relevant contrast (Brogaard, 2013; 36-37; Lyons, 2005; Prinz, 2013; Tye, 2000, 61). Perhaps after training in mandolins, being presented with mandolins reliably elicits a certain feeling of familiarity in you, and this feeling grounds a recognitional capacity for mandolins.

As against the suggestion that a feeling of familiarity grounds your capacity to recognize mandolins, Siegel develops a dilemma: either the relevant feeling of familiarity is representational, that is, attributes the trait being of a type that is known to one, or else the feeling of familiarity is not representational. If, on the first horn of the dilemma, the proposed feeling of familiarity is representational, then it is a cognitive state of some sort. Cognitive states come in two varieties: those that are revised in response to evidence that they are inaccurate and those that are not. The "mandolin" state is not revised in response to evidence that it is inaccurate; it might persist even if its subject should believe on excellent evidence that the perceived object is not really a mandolin. So the "mandolin" state is not an evidence-responsive cognitive state (for more on this, see Section 4.3). The "mandolin" state also is not any other sort of cognitive state because if it were, it would have to be a conscious, occurrent, extra-perceptual state, and the "mandolin" state does not seem to involve any such state (Siegel, 2010, 102-107).

If, on the other horn of the dilemma, the proposed feeling of familiarity is non-representational, then the explanation also fails, and for a rather surprising reason: there is no such thing as a non-representational feeling of familiarity. Siegel comes to this view by considering a case in which you see someone who elicits a feeling of familiarity in you. Siegel notes that were you to believe that this person is not known to you, the combination of this belief and your feeling of familiarity would likely elicit confusion in you. The best explanation of your confusion is that your feeling and your belief conflict, since your feeling represents the person as familiar, whereas your belief represents the person as unfamiliar. Taking this case as a paradigm, Siegel generalizes to the claim that all feelings of familiarity are representational (Siegel, 2010, 109-110).

One concern about Siegel's argument is that it is not clear that it generalizes to all feelings of familiarity. Suppose that while walking down a city sidewalk, you find yourself behind a woman who reminds you of your favorite, and long-deceased, aunt. You might experience a strong feeling of familiarity in response to this woman and at the very same time, think, "that woman is not known to me." Yet the combination of these states needn't cause any confusion in you. One explanation of your lack of confusion is that the feeling of familiarity is a non-representational emotion, a "raw feel." As such, it does not conflict with your thought that the woman before you is not known to you, so there is nothing for you to be confused about. If this is right, then at least some feelings of familiarity are non-representational. So there is no obvious barrier to claiming that in the "mandolin" case, such feelings ground your recognitional capacity for mandolins.

A different criticism of the argument's second premise is that the felt difference between your naïve and expert mandolin states is due to a shift in the distribution of your attention, not to the acquisition of a "mandolin" percept. Perhaps in your expert state, you effortlessly and automatically attend to the mandolin's distinguishing traits, such as its number of strings and style of handle, and this difference in turn brings about a difference in the overall character of your experience without resulting in or being explained by a "mandolin" representation (Block, 2014, 3; Nanay, 2011, 308-311; Prinz, 2013).

One way advocates of the argument have responded to this worry is to concede that even if some phenomenal contrasts might be explained by attentional differences, not all contrasts can be explained this way (Farennikova, 2013, 439; Nanay, 2011, 314; Siegel, 2013). Setting aside for the moment the "mandolin" case, consider a different 
case, one that involves the feature being jumpable-by-you. Suppose that you have never received any training in highjumping and you view a raised horizontal bar. You then undergo extensive training in high-jumping and subsequently view the very same raised bar. Plausibly, there will be a felt difference in your mental states, corresponding to the fact that in the first case, you do not represent the bar as jumpable-by-you, whereas in the second case, you do represent the bar as jump-able-by you. It would be difficult to explain this felt difference in terms of differences in attention, as it seems that even if you were to attend in both cases to (say) the very center of the bar, there might still be a phenomenal difference between the two states.

\section{3 | Third objection: the high-level representation is not perceptual}

The final objection to the phenomenal contrast argument rejects the argument's third premise, which states that the "mandolin" representation (if any) is a visual experience. One way of rejecting this premise is to endorse the view that the "mandolin" representation is a post-perceptual thought. Call this the cognitive explanation. On this view, you visually perceive merely the mandolin's shape and color, and this experience quickly triggers a thought with the content "that is a mandolin." (Mylopoulos, 2015; Prinz, 2013; Rips, 2011; Tye, 1995).

One argument in favor of the view that the "mandolin" representation is a visual experience is the felt unity argument, which begins with the observation that your visual experience of the mandolin's shape and color is felt to be unified with the accompanying "mandolin" representation in a way that, say, a pang of sadness that happens to trigger the thought that you need to buy light bulbs is not. The next step of the argument claims that this felt unity would be difficult to explain if the "mandolin" representation were a thought, whereas this felt unity would be easy to explain if the "mandolin" representation were itself a visual experience (Siegel, 2005, 279; Siegel, 2009, 534-535).

One worry about the felt unity argument is that there appear to be other cases in which a feeling of unity can arise between attitudes of different kinds. Suppose you learn that your roommate's tarantula has escaped its terrarium. Phobic of spiders, you are immediately filled with terror. It is plausible that these two states-the thought that the tarantula has escaped and the feeling of terror-will be felt to be unified in the relevant way, even though they belong to attitudes of different kind. The possibility of felt unity between attitudes of different kind clears the way for the advocate of the cognitive explanation to claim that in viewing the mandolin, your low-level visual experience of the mandolin's shape and color feels to be unified with the thought, "that is a mandolin."

Another argument advocates of high-level perception have employed against the cognitive explanation draws on the fact that the "mandolin" representation is fast, automatic, and unmediated by conscious inference. On the assumption that thoughts are typically slow, effortful, and mediated by conscious inference, it is unlikely that the "mandolin" representation is a thought (Bayne, 2011, 359-360; Farennikova, 2013, 435; Fish 2013, 50-52; Scholl \& Gao, 2013, 207-209). The problem with this argument is that there are independent grounds for thinking that many thoughts are fast, automatic, and unmediated by conscious inference (Evans, 2008). So it seems plausible that the "mandolin" representation might be such a thought (Rips, 2011).

A third argument against the cognitive explanation appeals to the fact that the "mandolin" representation can occur at the same time as a thought that conflicts with it. For instance, suppose that subsequent to your luthier training, you are presented with a mandolin-looking hologram. Even if you are aware that the object before you is a hologram and form the thought, "that is not a mandolin," it might nevertheless seem to you that the object before you is a mandolin. Since thoughts never or rarely conflict, it is unlikely that the "mandolin" representation is a thought (Bayne, 2009; Farennikova, 2013, 435; Siegel, 2010, 104-105).

One problem with this argument is that there appear to be many cases in which thoughts conflict, even when the relevant thoughts are both conscious and attended (see, e.g., Gertler, 2011; Mandelbaum, 2014a; Quilty-Dunn, 2015). For instance, superstitious views can persist despite one's better judgment that they are false (Huddleston, 2012). Likewise, certain highly intuitive but incorrect responses to mathematical puzzles can persist even after one learns those responses to be incorrect (Helton, 2015, 90-91; Mylopoulos, 2015, 768). So the fact that the "mandolin" 
representation can exist at the same time as a thought that conflicts with it does not establish that the "mandolin" representation is not a thought.

A more recent attempt to argue against the cognitive explanation claims that most thoughts have a certain nomic capacity to be rationally revised, whereas at least some perceptual states lack this capacity. If the "mandolin" state lacks this capacity, then it is unlikely that this state is a thought (Helton, 2015, 74-120). Note that in order to establish that the "mandolin" state lacks the relevant capacity to be rationally revised, it would not be enough to show that the "mandolin" state is in some circumstances unrevised in response to counter-evidence. Rather, it would have to be shown that the "mandolin" state is in all known circumstances unresponsive to counter-evidence, including ones in which the subject's motivation to make correct "mandolin" attributions is very high and in which the subject has sufficient time to incorporate the relevant counter-evidence. Whether the "mandolin" state would be revised in such cases is an open empirical question. ${ }^{5}$

So far, we have considered how the advocate of high-level perception might exclude the cognitive explanation, on which the "mandolin" representation is a thought. A different challenge claims that the "mandolin" representation is neither a perceptual state nor a thought, but is rather an attitude called a seeming (Brogaard, 2013, 37; Reiland, 2014; Sosa, 2007, 48, footnote 3; Sosa, 2015). One question about the seeming-based explanation is whether there is sufficient motivation for admitting the attitude of seeming into our ontology of mental kinds, particularly if this attitude is meant to be unreducible to more familiar cognitive attitudes.

\section{5 | EMERGING DEFENSES OF HIGH-LEVEL PERCEPTION}

The phenomenal contrast argument has dominated discussions of high-level perception, but recently, some alternative strategies of defending high-level perception have emerged. Here, I mention two of these: the first approach draws on cases in which it would appear that subjects represent an object's high-level features even though they fail to perceive any of that object's low-level features. The second approach draws on adaptation effects. ${ }^{6}$

\section{1 | High-level representation without low-level perception: unilateral neglect}

Unilateral neglect patients have difficulty reporting on objects that are presented to them on one side of their visual field, but under certain conditions, they can report on the action features of those objects. An object's action features are those features which permit it to be acted on in certain characteristic ways. Exemplar action features are edibility and climbability (Humphreys \& Riddoch, 2001; Riddoch, Edwards, Humphreys, West, \& Heafield, 1998, esp. 678).

Bence Nanay has argued that subjects with unilateral neglect visually perceive objects' action features, even though they do not perceive those objects' low-level features. His argument for this claim is that if we were to reject it, we would be forced into the odd position of saying that such subjects have no perceptual phenomenology when they view the relevant objects, even though there is "something it is like" for them to view such objects. Nanay further suggests that evidence from other, relevantly similar perceptual deficits might be used to establish the perception of other high-level features (Nanay, 2012, 242-244).

In reply to Nanay's claim that unilateral neglect patients perceive action features, Athanassios Raftopoulos has marshaled indirect evidence that in the same conditions in which subjects with unilateral neglect report on presented objects' action features, they also perceive those objects' low-level features, such as their shape and color. If this is right, it would undermine the motivation for claiming that such patients perceive action features (Raftopoulos, 2015, 352-355).

\section{2 | Adaptation effects}

Another emerging defense of high-level perception relies on adaptation effects. Several theorists have argued that if some mental state exhibits an adaptation effect, it is likely that that state is a perceptual state (Block, 2010, 57; Block, 
2014; Burr \& Ross, 2008; Di Bona, In preparation, Fish 2013; cf. Storrs, 2015). Adaptation effects occur whenever fixating on some object(s) with a particular trait makes some subsequently presented object seem to have an opposing trait.

In humans, adaptation effects are widespread, and some of them involve mental states that represent high-level features. For instance, visually fixating on a masculine face for some period can make a subsequently presented face appear to be more feminine than it otherwise would (Kaping, Bilson, \& Webster, 2002). Other results suggest that this effect cannot be wholly explained by a shift in low-level features. ${ }^{7}$

On a visual explanation of the masculine/feminine effect, the effect occurs between a visual experience of masculinity and a visual experience of femininity. If this explanation is correct, subjects visually perceive masculinity and femininity. On a cognitive explanation of the effect, the low-level visual experience of the first face's shape and color gives rise to a fast and automatic thought, "that is masculine." Then, a low-level visual experience of the second face's shape and color gives rise to a fast and automatic thought, "that is feminine." If this explanation is correct, subjects undergoing this effect do not visually perceive masculinity or femininity.

In favor of the visual explanation of the masculine/feminine effect is that adaptation effects have been established for a wide range of low-level visual features (Burr \& Ross, 2008; Fish 2013, 52). These results establish the plausibility of the visual explanation, but they do not suggest a reason to prefer this explanation to the cognitive explanation. Ned Block has offered such a reason, in the form of the claim that it is unlikely that adaptation effects ever occur between thoughts (Block, 2014, 7-8).

However, contra Block, there appear to be cases in which adaptation effects occur between thoughts. Consider the following:

You are looking through lists of houses for sale, which include each house's size. You first spend a long period carefully reading through a list of very large mansions. While going over this list, you think, without explicit inference or felt effort, 'what large houses!' Then, very suddenly, you happen to move to a list of medium-sized houses. You immediately think, without explicit inference or felt effort, 'what small houses!'

Here is one explanation of the case: you ordinarily would not judge the medium-sized houses to be small, but your being presented with them after pouring over a long list of mansions has momentarily shifted your standards for house sizes. Though this shift in your standards occurs outside of conscious awareness and without felt effort, it nevertheless contributes to your conscious thought, "what small houses!"

In this case, sustained exposure to objects with a particular trait results in a thought that certain subsequently presented objects have an opposing trait. So thoughts are susceptible to adaptation effects. Moreover, the effect in the "house" case is not unusual. We could develop similar cases for most any gradable feature: expressiveness, diligence, symmetry, brevity, roughness, femininity, and so on. Adaptation between thoughts would appear, then, to be not just possible but common. So it is not obvious that we should prefer the visual explanation of the masculine/feminine effect to the cognitive explanation.

In response to the claim that adaptation effects are ubiquitous in thought, Block can appeal to the fact that some high-level conscious states adapt in response to stimuli which are presented to subjects without their conscious awareness (e.g., Yang, Hong, \& Blake, 2010). Block supposes that it is implausible that conscious thoughts might be influenced by non-conscious thoughts, so he thinks it unlikely that a conscious state which adapts to a non-conscious state will turn out to be a thought (Block, 2014, 8-11).

The problem with the preceding response is that there is some evidence that non-conscious thoughts can influence conscious thoughts. ${ }^{8}$ So, it is at least feasible that non-conscious thoughts about contextual features (such as the sizes of objects) might contribute to the shifting of standards for those features, and in a way that influences conscious thoughts about whether subsequently presented objects exhibit those features (e.g., that is small). If this is right, then the fact that some conscious state adapts to a non-conscious state would not establish that the adapting state is a perceptual experience; it might also be a thought. 


\section{6 | SUMMARY}

To review, the question of whether we perceive high-level features may have implications for both epistemology and theory of action. One influential method of defending high-level perception is the phenomenal contrast method. This method is introspective only insofar as it relies on subjective report to ascertain the presence of a relevant phenomenal difference. The remaining steps in the argument consist of two inferences to the best explanation: one to establish that the relevant high-level feature is represented somehow, and one to establish that this representation is a perceptual experience.

Recently, other defenses of high-level perception have emerged. One approach appeals to certain perceptual deficits that appear to involve high-level representation in the absence of low-level perception. Another approach draws on evidence that high-level mental states exhibit adaptation effects and on the claim that only perceptual experiences exhibit such effects. This latter strategy warrants further scrutiny, as there is some evidence that thoughts can also exhibit such effects. ${ }^{9}$

\section{ENDNOTES}

${ }^{1}$ This example is from Siegel $(2010,121)$.

2 The claim that we can perceive high-level features echoes the claim made by many 20th century philosophers that we can perceive objects under a certain aspect, for example, that we can see dogs as dogs or flowers as flowers (see, e.g., Strawson, 1974, Wittgenstein, 1953). Despite the apparent similarities of these two claims-and despite their shared use of the "seeing as" locution-it is not obvious that the claims are equivalent. Consider that in the literature on aspect-perceiving, the paradigm cases of perceiving an object under one of its aspects are cases of sudden and dramatic shift, for example, you see some flowers as chalk scrawls on a wall but suddenly come to see them as flowers (Strawson, 1974). In contrast, in the literature on high-level perception, these dramatic, gestalt-shifting cases are generally regarded as poor candidates for high-level perception, since they are widely thought to be explained by post-perceptual attentional shifts and not by perception itself (see Section 4.2 in the main text). One explanation of this difference is that the two claims are not extensionally equivalent.

${ }^{3}$ Horgan and Tienson (2002), Kriegel (2007), Siewert (1998, 278-9), and Strawson (2010, 5-6) rely on the phenomenal contrast method for a different end, that of arguing that cognitive states have a proprietary feel. Bayne $(2009,2011)$ draws on behavioral contrasts to defend the perception of artifacts and the perception of one's own agency, respectively.

4 The use of the phenomenal contrast argument to defend the claim that we perceive natural kind features-such as being water and being a pine tree-has attracted special criticism. Many theorists have supposed that natural kind features are equivalent to molecular or other environmentally determined features, and they have supposed that such "hidden" aspects of the world do not make a contribution to phenomenal experience (Brogaard, 2013; Byrne, 2009; Lyons, 2005; Pautz, 2008, 23-25; Prinz, 2013; cf. Siegel, 2006, 2013). Notice that whatever the force of this worry about natural kind features, it does not seem to apply to at least some other proposed high-level percepts. For instance, the feature being $a$ chair is plausibly equivalent to some cluster of functional features such as being usable for sitting. It is feasible that such functional features might make a contribution to phenomenal experience, even if molecular or other 'hidden' micro-features do not (cf. Brogaard, 2013, 41).

${ }^{5}$ I argue elsewhere that at least some other high-level mental states, including some states about the intentions of others, lack the relevant capacity to be rationally revised and hence, are unlikely to be thoughts (Helton, 2015, 74-120).

${ }^{6}$ Di Bona (in preparation) uses adaptation effects as part of a phenomenal contrast argument. Other theorists use adaptation effects as part of an alternative approach to the phenomenal contrast argument (e.g., Fish 2013, 48; but see also Block, 2014, 4).

7 The effect obtains between non-faces and faces, for example, presenting subjects with "feminine" objects, such as tubes of lipstick, makes subsequently presented faces appear more masculine than they otherwise would (Javadi \& Wee, 2012). The effect also obtains between faces and bodies and between faces in silhouette and faces not in silhouette (Davidenko, Witthoft, \& Winawer, 2008, Palumbo, D'Ascenzo, \& Tommasi, 2015). Since the effect obtains between stimuli with dramatically different low-level features, it is unlikely that the effect is entirely due to the adaptation of low-level features.

${ }^{8}$ For example, when evaluating candidates for a management position in a construction company, subjects choose on the basis of gender, preferring male candidates to female ones. However, subjects explain their choices by citing features other than gender (Norton, Vandello, \& Darley, 2004). One explanation of this result is that subjects' gender biases are nonconscious thoughts (e.g., men are good at construction) which elicit conscious thoughts (e.g., he is more competent than her). These in turn explain subjects' explicit choices (Mandelbaum, 2014b). 
9 I am indebted to the following people for their feedback on this paper: Tom Avery, Ned Block, Bill Fish, Laura Gow, Ole Koksvik, Michelle Montague, Bence Nanay, Susanna Siegel, and Maarten Steenhagen. Special thanks to an anonymous referee.

\section{WORKS CITED}

Bayne, T. (2009). Perception and the reach of phenomenal content. The Philosophical Quarterly, 59(236), 385-404.

Bayne, T. (2011). The sense of agency. In F. Macpherson (Ed.), The senses: Classic and contemporary philosophical perspectives. (pp. 355-374). Oxford: Oxford University Press.

Begby, E. (2011). Review of Tyler Burge, origins of objectivity. Notre Dame Philosophical Reviews, 2011(2).

Block, N. (2010). Attention and mental paint. Philosophical Issues, 20, 23-63.

Block, N. (2014). Seeing-as in the light of vision science. Philosophy and Phenomenological Research, 89(1), 650-572.

Brogaard, B. (2013). Do we perceive natural kind properties? Philosophical Studies, 162(1), 35-42.

Brogaard, B., \& Chomanski, B. (2015). Cognitive penetrability and high-level properties in perception: Unrelated phenomena? Pacific Philosophical Quarterly, 96(4), 469-486.

Burr, D., \& Ross, J. (2008). A visual sense of number. Current Biology, 18, 425-428.

Butterfill, S. (2009). Seeing causings and hearing gestures. The Philosophical Quarterly, 59(236), 405-428.

Butterfill, S. A. (2015). Perceiving expressions of emotion: What evidence could bear on questions about perceptual experience of mental states? Consciousness and Cognition, 36, 438-451.

Byrne, A. (2009). Experience and content. The Philosophical Quarterly, 59(236), 429-451.

Chudnoff, E. (2015). Phenomenal contrast arguments for cognitive phenomenology. Philosophy and Phenomenological Research, 91(1), 82-104.

Cullison, A. (2010). Moral perception. European Journal of Philosophy, 18(2), 159-175.

Davidenko, N., Witthoft, N., \& Winawer, J. (2008). Gender aftereffects in face silhouettes reveal face-specific mechanisms. Visual Cognition, 16(1), 99-103.

Di Bona, E. (In preparation). Towards a rich view of auditory experience.

Evans, J. S. B. (2008). Dual-processing accounts of reasoning, judgment, and social cognition. Annual Review of Psychology, 59 , 255-278.

Farennikova, A. (2013). Seeing absence. Philosophical Studies, 166(3), 429-454.

Fish, W. (2013). High-level properties and visual experience. Philosophical Studies, 162, 43-55.

Gertler, B. (2011). Self-knowledge and the transparency of belief. In A. Hatzimoysis (Ed.), Self-Knowledge. (pp. 125-145). Oxford: Oxford University Press.

Helton, G. (2015). Two worlds, one mind: The divide between perception and belief (Unpublished doctoral dissertation). New York University, New York.

Horgan, T., \& Tienson, J. (2002). The intentionality of phenomenology and the phenomenology of intentionality. In D. Chalmers (Ed.), Philosophy of Mind: Classical and Contemporary Readings. (pp. 520-533). New York: Oxford University Press.

Huddleston, A. (2012). Naughty beliefs. Philosophical Studies, 160(2), 209-222.

Humphreys, G. W., \& Riddoch, M. J. (2001). Detection by action: Neuropsychological evidence for action-defined templates in search. Nature Neuroscience, 4(1), 84-88.

Javadi, A. H., \& Wee, N. (2012). Cross-category adaptation: Objects produce gender adaptation in the perception of faces. PloS One, 7(9), e46079.

Kaping, D., Bilson, A. C., \& Webster, M. A. (2002). Adaptation and categorical judgments of faces. Journal of Vision, 2 (7), 564.

Koksvik, O. (2015). Phenomenal contrast: A critique. American Philosophical Quarterly, 52(4), 321-334.

Kriegel, U. (2007). The phenomenologically manifest. Phenomenology and the Cognitive Sciences, 6(1-2), 115-136.

Logue, H. (2013). Visual experience of natural kind properties: Is there any fact of the matter? Philosophical Studies, 162(1), 1-12.

Lyons, J. (2005). Clades, capgras, and perceptual kinds. Philosophical Topics, 33(1), 185-206.

Macpherson, F. (2011). Introduction: The admissible contents of experience. In K. Hawley, \& F. Macpherson (Eds.), The admissible contents of experience. (pp. 1-15). Oxford: Wiley-Blackwell.

Macpherson, F. (2012). Cognitive penetration of colour experience: Rethinking the issue in light of an indirect mechanism. Philosophy and Phenomenological Research, 84(1), 24-62. 
Mandelbaum, E. (2014a). Attitude, inference, association: On the propositional structure of implicit bias. Noûs, 1-30.

Mandelbaum, E. (2014b). Thinking is believing. Inquiry, 57(1), 55-96.

Masrour, F. (2011). Is perceptual phenomenology thin? Philosophy and Phenomenological Research, 83(2), 366-397.

Mylopoulos, M. I. (2015). Agentive awareness is not sensory awareness. Philosophical Studies, 172(3), 761-780.

Nanay, B. (2011). Do we see apples as edible? Pacific Philosophical Quarterly, 92(3), 305-322.

Nanay, B. (2012). Perceptual phenomenology. Philosophical Perspectives, 26(1), 235-246.

Nanay, B. (2013). Between perception and action. Oxford: Oxford University Press.

Norton, M. I., Vandello, J. A., \& Darley, J. M. (2004). Casuistry and social category bias. Journal of Personality and Social Psychology, 87(6), 817.

O'Callaghan, C. (2008). Object perception: Vision and audition. Philosophy Compass, 3(4), 803-829.

Palumbo, R., D'Ascenzo, S., \& Tommasi, L. (2015). Cross-category adaptation: Exposure to faces produces gender aftereffects in body perception. Psychological Research, 79(3), 380-388.

Pautz, A. (2008). What are the contents of experiences? The Philosophical Quarterly, 59(236), 483-507.

Prinz, J. (2013). Siegel's get rich quick scheme. Philosophical Studies, 1-9.

Pylyshyn, Z. (1999). Is vision continuous with cognition?: The case for cognitive impenetrability of visual perception. Behavioral and Brain Sciences, 22(03), 341-365.

Quilty-Dunn, J. (2015). Believing in perceiving: Known illusions and the classical dual-component theory. Pacific Philosophical Quarterly, 96(4), 550-575.

Raftopoulos, A. (2015). What unilateral visual neglect teaches us about perceptual phenomenology. Erkenntnis, 80(2), 339-358.

Reiland, I. (2014). On experiencing high-level properties. American Philosophical Quarterly, 177-188.

Riddoch, M. J., Edwards, M. G., Humphreys, G. W., West, R., \& Heafield, T. (1998). Visual affordances direct action: Neuropsychological evidence from manual interference. Cognitive Neuropsychology, 15(6-8), 645-683.

Rips, L. J. (2011). Causation from perception. Perspectives on Psychological Science, 6(1), 77-97.

Scholl, B. J., \& Gao, T. (2013). Perceiving animacy and intentionality: Visual processing or higher-level judgment? In M. D. Rutherford, \& V. A. Kuhlmeier (Eds.), Social perception: Detection and interpretation of animacy, agency, and intention. (pp. 197-230). Cambridge, MA: MIT Press.

Scholl, B. J., \& Tremoulet, P. D. (2000). Perceptual causality and animacy. Trends in Cognitive Sciences, 4(8), $299-309$.

Siegel, S. (2005). The phenomenology of efficacy. Philosophical Topics, 33(1), 265-284.

Siegel, S. (2006). Which properties are represented in perception? In T. Gendler, \& J. Hawthorne (Eds.), Perceptual experience. (pp. 481-503). Oxford: Oxford University Press.

Siegel, S. (2007). How can we discover the contents of experience? The Southern Journal of Philosophy, 45(S1), $127-142$.

Siegel, S. (2009). The visual experience of causation. The Philosophical Quarterly, 59(236), 519-540.

Siegel, S. (2010). The contents of visual experience. Oxford: Oxford University Press.

Siegel, S. (2013). Replies to Campbell, Prinz, and Travis. Philosophical Studies, 1-19.

Siegel, S. (2014). Affordances and the contents of perception. In B. Brogaard (Ed.), Does perception have content? (pp. 39-76). Oxford: Oxford University Press.

Siewert, C. (1998). The significance of consciousness. Princeton: Princeton University Press.

Silins, N. (2013). The significance of high-level content. Philosophical Studies, 162(1), 13-33.

Sosa, D. (2015). What does it matter what it's like? Philosophical Issues, 25(1), 224-242.

Sosa, E. (2007). Apt belief and reflective knowledge, volume 1: A virtue epistemology. Oxford: Oxford University Press.

Storrs, K. R. (2015). Are high-level aftereffects perceptual? Frontiers in Psychology, 6, 157.

Strawson, G. (2010). Mental reality (2nd ed.). Cambridge, MA: MIT Press.

Strawson, P. F. (1974). Imagination and perception. In P. F. Strawson (Ed.), Freedom and resentment and other essays. Methuen: Methuen Publisher.

Toribio, J. (2015a). Social vision: Breaking a philosophical impasse? Review of Philosophy and Psychology, 6(4), 611-615.

Toribio, J. (2015b). Visual experience: Rich but impenetrable. Synthese, 1-18.

Tye, M. (1995). Ten problems of consciousness. Cambridge, MA: MIT Press.

Tye, M. (2000). Consciousness, color and content. Cambridge, MA: MIT Press. 
Van Gulick, R. (1994). Deficit studies and the function of phenomenal consciousness. In G. Graham, \& G. Lynn Stephens (Eds.), Philosophical psychopathology. (pp. 25-49). Cambridge, MA: MIT Press.

Wisnewski, J. J. (2015). The case for moral perception. Phenomenology and the Cognitive Sciences, 14(1), 129-148.

Wittgenstein, L. (1953). Philosophical investigations, trans. G. E. M. Anscombe. Oxford: Blackwell.

Yang, E., Hong, S. W., \& Blake, R. (2010). Adaptation aftereffects to facial expressions suppressed from visual awareness. Journal of Vision, 10(12), 24-24.

How to cite this article: Helton, G. (2016), Recent issues in high-level perception, Philosophy Compass, 11, 851-862. doi: 10.1111/phc3.12383

\section{AUTHOR BIOGRAPHY}

Grace Helton is a Cotsen Postdoctoral Fellow in the Society of Fellows at Princeton University. Her areas of research include: the perception-cognition divide, the nature of belief, knowledge of other minds, and the psychology of prejudice. 